\title{
Microwave ablation for colorectal cancer metastasis to the liver: a single-center retrospective analysis
}

\author{
Emily A. Knott ${ }^{1 \wedge}$, Timothy J. Ziemlewicz ${ }^{1 \wedge}$, Sam J. Lubner ${ }^{2,3}$, John F. Swietlik ${ }^{1}$, Sharon M. Weber ${ }^{1,3,4}$, \\ Annie M. Zlevor ${ }^{1}$, Colin Longhurst ${ }^{3,5}$, J. Louis Hinshaw ${ }^{1,6}$, Meghan G. Lubner ${ }^{1}$, Daniel L. Mulkerin ${ }^{2,3}$, \\ Daniel E. Abbott ${ }^{3,4}$, Dustin Deming ${ }^{2,3}$, Noelle K. LoConte ${ }^{2,3}$, Nataliya Uboha $^{2,3}$, Allison B. Couillard ${ }^{1}$, \\ Shane A. Wells ${ }^{1}$, Paul F. Laeseke ${ }^{1,3}$, Marci L. Alexander ${ }^{1}$, Fred T. Lee Jr ${ }^{1,3,6,7}$
}

${ }^{1}$ Department of Radiology, University of Wisconsin-Madison, Madison, WI, USA; ${ }^{2}$ Department of Medicine, University of Wisconsin-Madison, Madison, WI, USA; ${ }^{3}$ Carbone Cancer Center, University of Wisconsin-Madison, Madison, WI, USA; ${ }^{4}$ Department of Surgery, University of Wisconsin-Madison, Madison, WI, USA; ${ }^{5}$ Department of Biostatistics and Medical Informatics, University of Wisconsin-Madison, Madison, WI, USA; ${ }^{6}$ Department of Urology, University of Wisconsin-Madison, Madison, WI, USA; ${ }^{7}$ Department of Biomedical Engineering, University of Wisconsin-Madison, Madison, WI, USA

Contributions: (I) Conception and design: EA Knott, TJ Ziemlewicz, SJ Lubner, SM Weber, C Longhurst, PF Laeseke, FT Lee Jr; (II) Administrative support: ML Alexander, TJ Ziemlewicz, FT Lee Jr; (III) Provision of study materials or patients: TJ Ziemlewicz, SJ Lubner, SM Weber, JL Hinshaw, MG Lubner, DL Mulkerin, DE Abbott, D Deming, NK LoConte, N Uboha, SA Wells, PF Laeseke, ML Alexander, FT Lee Jr; (IV) Collection and assembly of data: EA Knott, JF Swietlik, AM Zlevor, C Longhurst, AB Couillard; (V) Data analysis and interpretation: EA Knott, C Longhurst; (VI) Manuscript writing: All authors; (VII) Final approval of manuscript: All authors.

Correspondence to: Fred T. Lee Jr, MD. 600 Highland Ave, Madison, WI 53792, USA. Email: ftlee@wisc.edu.

Background: The purpose of this study is to evaluate the safety and intermediate-term efficacy of percutaneous microwave (MW) ablation for the treatment of colorectal liver metastases (CRLM) at a single institution.

Methods: A retrospective review was performed of all CRLM treated with MW ablation from 3/2011 to 7/2020 (102 tumors; 72 procedures; 57 patients). Mean age was 60 years (range, 36-88) and mean tumor size was $1.8 \mathrm{~cm}$ (range, $0.5-5.0 \mathrm{~cm}$ ). The patient population included 19 patients with extra-hepatic disease. Chemotherapy (pre- and/or post-ablation) was given in $98 \%$ of patients. Forty-five sessions were preceded by other focal CRLM treatments including resection, ablation, radiation, and radioembolization. Kaplan-Meier curves were used to estimate local tumor progression-free survival (LTPFS), disease-free survival (DFS), and overall survival (OS) and multivariate analysis (Cox Proportional Hazards model) was used to test predictors of OS.

Results: Technical success (complete ablation) was $100 \%$ and median follow-up was 42 months (range, 1-112). There was a $4 \%$ major complication rate and an overall complication rate of $8 \%$. Local tumor progression (LTP) rate during the entire study period was 4/98 (4\%), in which 2 were retreated with MW ablation for a secondary LTP-rate of 2\%. LTP-free survival at 1, 3, and 5 years was $93 \%, 58 \%$, and $39 \%$ and median LTP-free survival was 48 months. OS at 1, 3, and 5 years was 96\%, 66\%, 47\% and median OS was 52 months. There were no statistically significant predictors of OS.

Conclusions: MW ablation of hepatic colorectal liver metastases appears safe with excellent local tumor control and prolonged survival compared to historical controls in selected patients. Further comparative studies with other local treatment strategies appear indicated.

Keywords: Colorectal cancer; ablation; hepatic metastasis; treatment of metastasis; liver targeted therapy

^ ORCID: Emily A. Knott, 0000-0002-0156-7696; Timothy J. Ziemlewicz, 0000-0002-7033-1062; John F. Swietlik, 0000-0002-7180-794X. 
Submitted Mar 23, 2021. Accepted for publication Jul 11, 2021.

doi: 10.21037/jgo-21-159

View this article at: https://dx.doi.org/10.21037/jgo-21-159

\section{Introduction}

Colorectal cancer is the second leading cause of cancer death worldwide (1). Approximately $50 \%$ of colorectal cancer patients will eventually develop liver metastases (CRLM) (2), and surgery is the primary curative treatment option when feasible. If patients are able to undergo surgical resection, 5-year overall survival (OS) rates are approximately $31-60 \%$ in carefully selected patients $(3,4)$. Unfortunately, less than $20 \%$ of patients with CRLM are candidates for resection due to co-morbidities or the number, size, and distribution of tumors $(5,6)$.

Percutaneous thermal ablation remains a potentially curative option for some patients with CRLM who are not surgical candidates (7). Radiofrequency (RF) ablation is the most widely used ablative modality for CRLM, and longterm studies have shown improved survival with low rates of complications. However, most RF studies demonstrate a high rate of local tumor progression (LTP) and an inability to treat larger tumors, likely due to small ablation zones resulting in inadequate margins (8-14). More recently, microwave (MW) ablation has gained popularity for the treatment of liver tumors due to a number of technological advantages, including higher applied temperatures, multiple probe synergy, less susceptibility to the heat-sink effect, larger ablation zones, possibly improved local tumor control, and some data which suggests equivalent OS to surgical resection (15-20). However, most hepatic MW literature is for hepatocellular carcinoma, and the clinical experience with MW for CRLM is limited to just a few studies (18,21-23). These reports are quite heterogenous and include a mixture of percutaneous and intraoperative cases, are limited to the use of single probe devices, or use MW systems not approved for human use worldwide (14,21-26).

The purpose of this single-center single-arm retrospective study is to report the technical and intermediate-term oncological outcomes and complications after percutaneous MW ablation of CRLM from our multi-disciplinary tertiary care oncologic practice.

\section{Methods}

Institutional review board approval was obtained to deidentify a clinical database for research purposes, and a waiver of informed consent was granted for this retrospective study (University of Wisconsin-Madison Health Sciences IRB; ID: 2012-0519). There was no industry support for this publication.

The study was conducted in accordance with the Declaration of Helsinki (as revised in 2013). We present the following article in accordance with the STROBE reporting checklist (available at https://dx.doi.org/10.21037/jgo-21-159).

\section{Patient selection}

All patients who underwent percutaneous MW ablation for CRLM between March 2011 and July 2020 at a single academic medical center were included. Treatment decisions were made by a multidisciplinary team of radiologists, medical oncologists, and oncologic and transplant surgeons at a consensus conference. The decision to treat was based upon age, comorbidities, tumor size, location and histology, treatment status, proximity of non-target anatomy, and patient preference. In general, patients that underwent MW ablation were technically unresectable or were otherwise poor surgical candidates due to co-morbidities, anatomic location of tumors, or recent prior surgery. MW has been the thermal modality of choice at the study institution since 2011 and was performed by one of seven radiologists with 1-25 years of percutaneous ablation experience.

\section{Microwave ablation procedure}

Procedures were performed in a dedicated interventional computed tomography (CT) suite (Optima $580 \mathrm{~W}$; GE Healthcare, Waukesha, WI, USA) under general anesthesia. After 2018, high frequency jet ventilation (HFJV) became the anesthesia standard due to decreased hepatic motion (27). Ultrasound was used by default for antenna placement (US; LOGIQ E9 or E10, GE Healthcare). When the lesion was 
not visibly by US, CT fluoroscopy guidance was used.

A 2.45-GHz, multiprobe, gas-cooled MW ablation system was used for all cases (NeuWave Microwave Ablation System, Ethicon Inc., Madison, WI, USA). The treatment duration and power were determined by the operating physician based on tumor size, proximity to vulnerable structures (particularly central bile ducts and adjacent bowel loops), and real-time monitoring. Procedures were monitored primarily by US to ensure that the visible zone of gas encompassed the tumor and a target ablative margin of 5-10 $\mathrm{mm}$. At procedure completion, a contrast-enhanced CT was performed to determine technical success and complications. If residual tumor or an inadequate margin was suspected, repeat ablation was performed in the same session.

\section{Data collection}

Data was collected from an institutional database, electronic medical record, and image storage system (McKesson, Alpharetta, GA, USA). Images, dictations, and clinic notes were reviewed for procedural data, oncologic outcomes, and complications. All procedural and follow-up metrics were reported using established criteria (28). Technical success (ablation zone encompasses target tumor plus an ablative margin) was determined on the immediate postprocedure CT (28), and technique efficacy on the first scan $~ 1$-month post-ablation (28). Other metrics reported included: location and pathology of the primary tumor, pre-ablation CEA, tumor size and number, chemotherapy, $K R A S / B R A F$ status, metastases, prior CRLM interventions, complications, LTP, LTP-free survival (LTPFS), diseasefree survival (DFS), and OS, which was defined from the date of the first MW to the date of death or date that the patient was last known to be alive (28).

\section{Complications}

Peri-procedural complications were monitored and recorded during an overnight observation. Delayed complications were evaluated with follow-up imaging and clinic visits. Complications were categorized according to the Society of Interventional Radiology (SIR) classification system for complications by outcome (29).

\section{Statistical analysis}

The Kaplan-Meier method was used for survival analyses, which included LTPFS, DFS, and OS. Multivariate analysis was performed using the Cox Proportional Hazards model to test predictors of shortened OS (30). LTPFS was defined as the time period from ablation until radiologic evidence of recurrence or latest imaging follow-up (28). Patients that did not have follow-up imaging were excluded from the calculation of technique efficacy and LTP rate. DFS was defined as the time period from ablation to evidence of new disease or latest imaging follow-up (first session was used for patients with multiple sessions) (28). Patients with extrahepatic disease present at the time of ablation were excluded from DFS. Cox model $\mathrm{P}$ values were derived using two-sided Wald tests, where the null hypothesis, $\mathrm{H}_{0}$ : $\beta=0$, was tested against the alternative, $H_{1}: \beta \neq 0$, for each coefficient. $\mathrm{P}<0.05$ was considered significant for all statistical results. All analyses were performed using $\mathrm{R}(\mathrm{V}$ 4.0.3).

\section{Results}

The study population consisted of 102 consecutive CRLM treated in 57 patients ( 22 female, 35 male) during 72 sessions (Table 1). The mean patient age was $60 \pm 12$ years (range, 36-88). Mean tumor diameter was $1.8 \pm 1.0 \mathrm{~cm}$ (median: $1.6 \mathrm{~cm}$; range, $0.5-5.0)$. Tumors treated in a single session ranged from $1-6$ : one tumor $(n=56)$, two $(n=8)$, three $(n=4)$, four $(n=3)$, and six $(n=1)$. Extrahepatic disease was present in 19 patients at the time of ablation, including lung metastases $(\mathrm{n}=11)$, lymph nodes $(\mathrm{n}=3)$, and multiple sites of metastasis $(\mathrm{n}=5)$. In five procedures, the primary tumor had not yet been resected but was planned for a later date. Ten sessions were part of a prospective multistage treatment plan in which the ablation was followed by surgical resection of remaining liver disease.

Chemotherapy was given to $98 \%$ of patients: $88 \%$ prior to ablation and $74 \%$ after. Thirty patients $(53 \%)$ had prior liver-directed therapies including hepatic resection, ablation, SBRT, and radioembolization. Ninety-nine tumors were adenocarcinomas (97\%), two were squamous cell (2\%), and one was composite adeno-/squamous/neuro-endocrine (1\%). Twenty-four patients had a KRAS mutatation, two had a $B R A F$ mutation, and $K R A S / B R A F$ testing was not performed in 28 patients. 
Table 1 All patient, procedure, and tumor characteristics

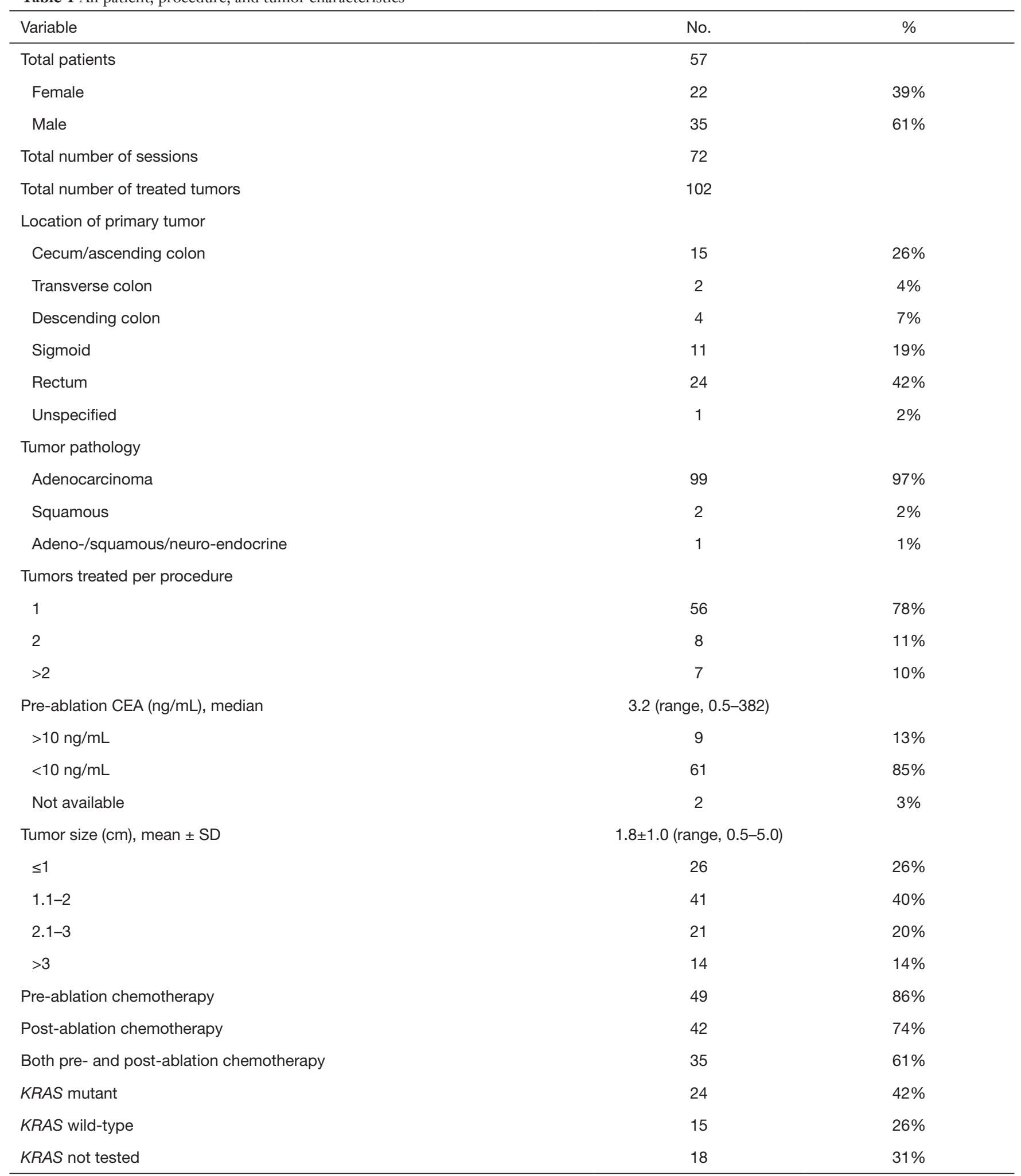

Table 1 (continued) 
Table 1 (continued)

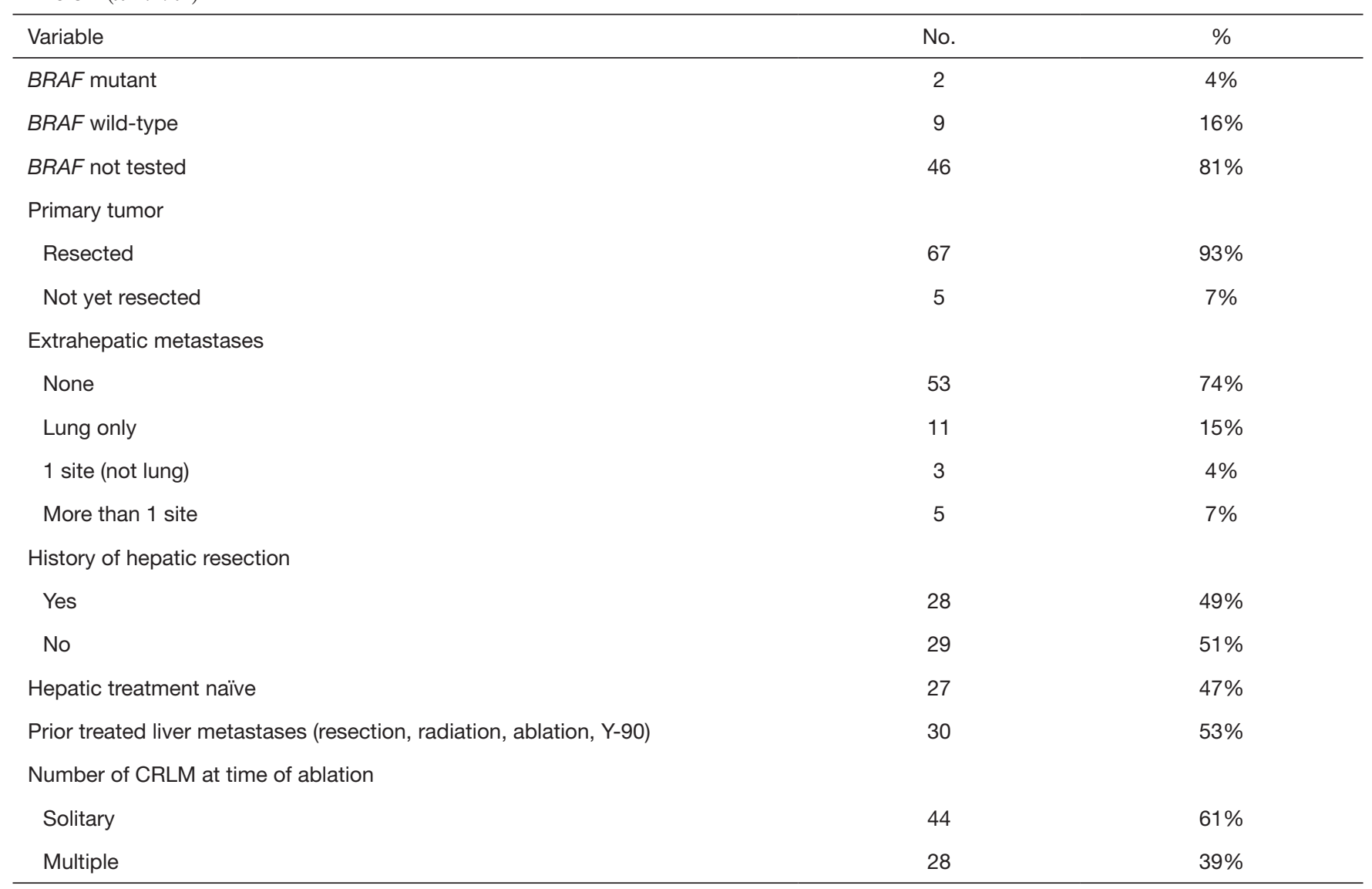

CEA, carcinoembryonic antigen; CRLM, colorectal liver metastases.

\section{Ablation procedure, technical success, and technique efficacy}

Technical success was $100 \%$ (complete ablation at the time of the procedure). The mean treatment time was $6.9 \pm 2.6$ minutes (range, $3-15$ ) with a mean power of 68.1 \pm 10.4 Watts (range, 55-112) per tumor. Two antennas were most commonly used per tumor (range, 1-3).

Median patient follow-up was 42 months (range, 1-112) with two patients lost to follow-up before a one month $\mathrm{CT}$ and thus were not included in follow-up statistics. Technique efficacy (complete treatment at 1 month postablation) was achieved in 98/100 (98\%) of tumors. These technique failures both occurred within the first 14 months of the introduction of MW. One patient had surgery (lesion not amenable to ablation) and the other had palliative chemotherapy and radiation for residual and extrahepatic disease.

\section{Complications (Table 2)}

The major complication rate was $4 \%(3 / 72)$, with an overall rate of $8 \%(6 / 72)$. There were three major procedurerelated complications: Tract seeding in a patient that had a recent biopsy along a similar trajectory; bile leak and abscess which resolved with drainage; and pulmonary emboli that resolved with anti-coagulation. Minor complications included asymptomatic pneumothorax $(\mathrm{n}=2)$ not requiring chest tubes, and body wall arterial bleeding $(\mathrm{n}=1)$ contemporaneously cauterized without sequela. There were no deaths within 30 days after ablation. 
Table 2 Complications after MW ablation

\begin{tabular}{lc}
\hline Complication & $\mathrm{N}$ \\
\hline Major complications & 1 \\
Bile leak treated with drain placement (Grade D) & 1 \\
$\begin{array}{l}\text { Pulmonary embolism treated with anticoagulation } \\
\text { (Grade D) }\end{array}$ & \\
$\begin{array}{l}\text { Tract seeding treated with systemic chemotherapy } \\
\text { (Grade E) }\end{array}$ & 1 \\
Minor complications & \\
$\begin{array}{l}\text { Pneumothorax treated with pleural blood patch } \\
\text { (Grade B) }\end{array}$ & 2 \\
$\begin{array}{l}\text { Muscle arterial bleeding resolved with cautery } \\
\text { (Grade B) }\end{array}$ & 1 \\
Total (rate) & $6(8.3 \%)$ \\
\hline
\end{tabular}

\section{OS}

Median OS was 52 months (Figure 1). Survival at 1, 3, and 5 years was $96 \%, 66 \%$, and $47 \%$. For patients that died, the causes of death were progressive cancer $(n=14)$, subdural hematoma $(\mathrm{n}=1)$, or unknown causes $(\mathrm{n}=6)$.

\section{Impact of tumor characteristics on survival (Table 3, Figure 2)}

Multivariate analysis demonstrated no statistically significant predictors of OS. Although not significant, a slight association between history of hepatic resection $(\mathrm{P}=0.06)$ and reduced hazard of death was observed. There also was a slight association observed between presence of extrahepatic disease $(\mathrm{P}=0.07)$ and LTP $(\mathrm{P}=0.07)$ independently increasing hazard of death. The size of the tumor $(>3 v s .<3 \mathrm{~cm}$ ), number of tumors (solitary $v s$. multiple), KRAS status, and CEA were not associated with a shortened OS.

\section{Disease progression and DFS}

The overall DFS at 1, 3, and 5 years was $34 \%, 21 \%, 10 \%$ and median DFS was 8 months (Figure 3). New CRLM remote from the ablation site occurred in $52 \%(24 / 46$;
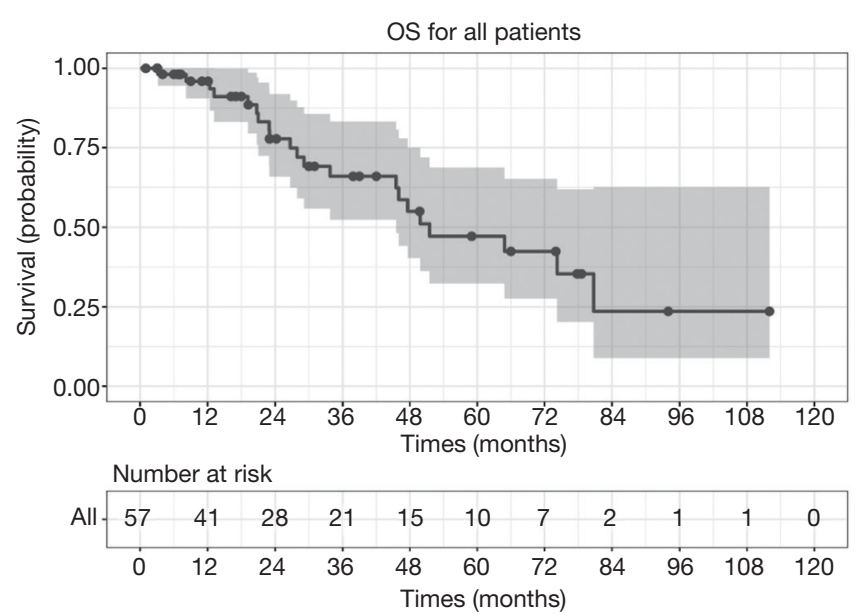

Figure 1 Overall survival Kaplan-Meier curve with $95 \%$ confidence bands.

11 patients excluded with lack of follow-up and/or liver disease present at time of ablation). Extrahepatic disease occurred or progressed in 55\% (30/55; 2 patients excluded due to lack of follow-up). Sites of extrahepatic disease: pulmonary nodules and thoracic lymph nodes $(n=16)$, abdominal/pelvic masses $(\mathrm{n}=8)$, abdominal/pelvic lymph nodes $(\mathrm{n}=5)$, brain metastasis $(\mathrm{n}=1)$.

\section{LTP, management of LTP, and LTP free survival (LTPFS)}

The LTP rate was 4/98 (4\%) per tumor and 4/53 (8\%) per patient (Table 4, Figure 4; note: 4 patients were excluded due to lack of technique efficacy and/or follow-up). One of four patients with LTP was identified within 1-year post-ablation, two within 2 years, and one at 4 years. Two were retreated with MW for a secondary LTP-rate of 2\% (Figure 5). The tumors not re-treated with MW were treated with surgery or palliative chemotherapy due to the inability for repeat ablation $(n=1)$ and concomitant detection of multifocal disease $(\mathrm{n}=1)$. LTPFS rate at 1,3 , and 5 years was $93 \%, 58 \%$, and $39 \%$ and median LTPFS was 48 months (Figure 4). Two of three non-adenocarcinoma patients had recurrences: combined local/intrahepatic/distant tumor progression $(\mathrm{n}=1)$ and intrahepatic/distant tumor progression $(n=1)$. 
Table 3 Results of multivariate analysis for predictors of overall survival

\begin{tabular}{|c|c|c|c|}
\hline Predictor & No. of patients & Hazard ratio $[95 \% \mathrm{Cl}]$ & $P$ value \\
\hline Male & 35 & $1.1[0.2,5.2]$ & 0.92 \\
\hline Female & 22 & & \\
\hline Age (years) & & $1.0[0.9,1.1]$ & 0.81 \\
\hline \multicolumn{4}{|c|}{ Prior liver resection } \\
\hline Yes & 28 & $0.3[0.1,1.1]$ & 0.06 \\
\hline No & 29 & & \\
\hline \multicolumn{4}{|c|}{ No. of CRLM present } \\
\hline Single & 34 & $0.3[0.1,1.3]$ & 0.12 \\
\hline \multicolumn{4}{|l|}{ CEA (ng/mL) } \\
\hline$>10 \mathrm{ng} / \mathrm{mL}$ & 8 & $1.4[0.4,5.4]$ & 0.61 \\
\hline$<10 \mathrm{ng} / \mathrm{mL}$ & 47 & & \\
\hline \multicolumn{4}{|c|}{ KRAS mutation } \\
\hline Wild-type & 15 & $1.4[0.3,5.4]$ & 0.65 \\
\hline Mutant & 24 & & \\
\hline \multicolumn{4}{|c|}{ Extrahepatic disease } \\
\hline Yes & 15 & $4.0[0.9,17.3]$ & 0.07 \\
\hline
\end{tabular}

Tumor size is the largest tumor in the procedure for those with multiple tumors treated. See OS curves (Figure 4). Cl, 95\% confidence interval; OS, overall survival.

\section{Discussion}

Treating hepatic colorectal metastases with thermal ablation is not new, but the vast predominance of available data is from centers in which radiofrequency is the dominant ablation modality. Microwave is a newer technology that creates larger, hotter, and faster ablation zones when compared to RF (15-19). However, there is a paucity of MW data for treating CRLM, and it remains unclear as to whether the physical advantages of microwave result in improved patient outcomes. Prior MW studies have been performed with a mixture of laparoscopic and percutaneous approaches, CT and/or US guidance, single rather than multiple probe systems, and with devices that are not approved for worldwide use (14,21-26,31). The results of this study demonstrate that percutaneous ultrasound-guided MW ablation for selected colorectal liver metastases is 
Hepatic resection prior to ablation

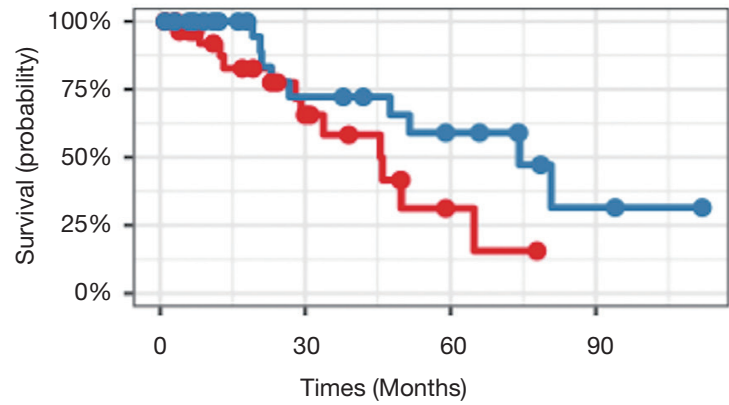

Extrahepatic Disease

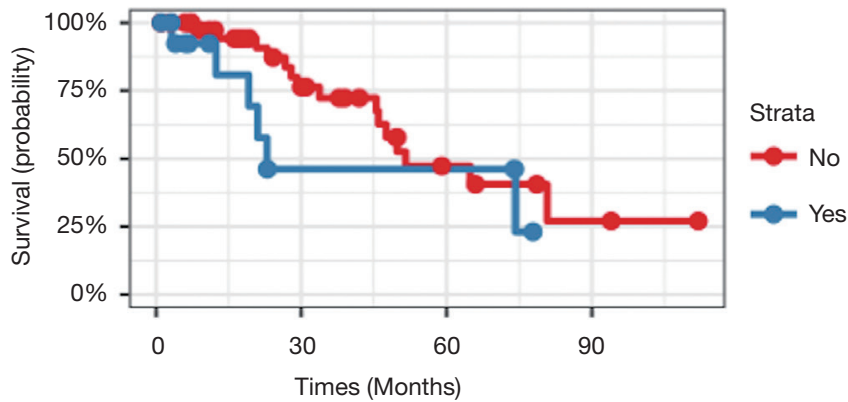

Patient has more than one tumor or tumor greater than $3 \mathrm{~cm}$

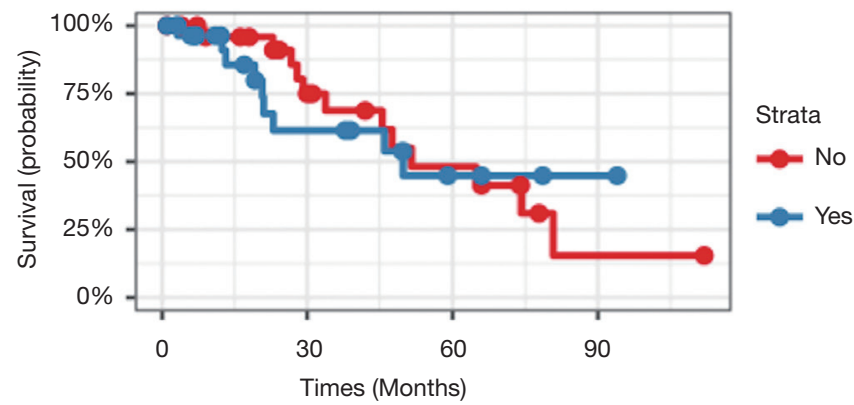

KRAS

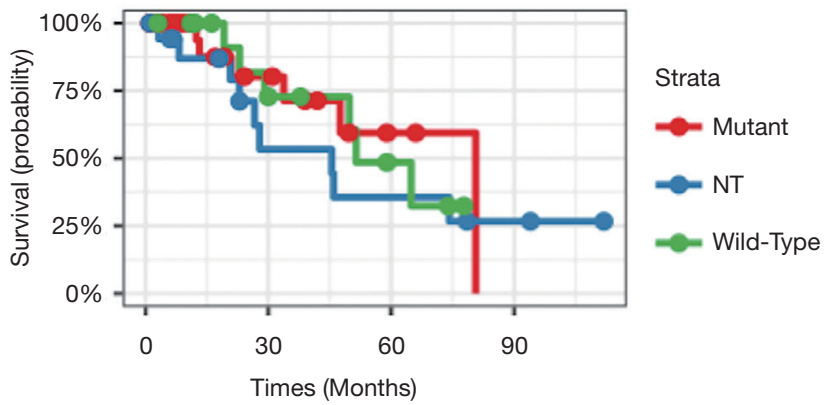

LTP

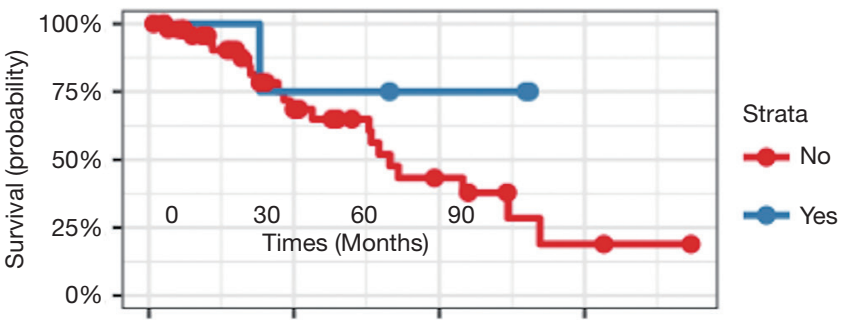

Figure 2 Overall survival Kaplan-Meier analysis for predicting factors that influence OS. OS, overall survival.

associated with few serious complications, high rates of local tumor control, and prolonged survival in selected patients.

The effectiveness of an ablation modality to destroy a targeted tumor is best described by LTP. The LTP rate was low in this study ( $4 \%$ per tumor and $8 \%$ per patient) and there was no obvious correlation between LTP and tumor size, genetic mutations, or original site of disease (Table 4). Other recent studies of MW for CRLM report LTP rates ranging from $24-38 \%(23,31,32)$. Comparatively, LTP rates for RF range from $6-51 \%(8-10,23,33-36)$ and $11-25 \%$ for cryoablation $(37,38)$ (Table 5). One matched cohort study suggests that LTP is lower for MW than for RF (6 vs. 20\%, 
$\mathrm{P}=0.01$ ) (21), however patients in that study were treated during open liver surgery, a much different procedure than the percutaneous approach described herein.

Several technical reasons that could contribute to the low reported LTP rates include experienced operators at a high-volume ablation center, careful patient selection, the use of ultrasound to precisely place probes and monitor the ablation, a multiprobe $M W$ system that produces thermal and electrical synergy, and immediate post-ablation CT with re-ablation of positive or close margins $(8,16,40-43)$. The relative contribution of each of these factors to the overall results is unknown but it is possible that the use of multiple antennas played a significant role. For example,

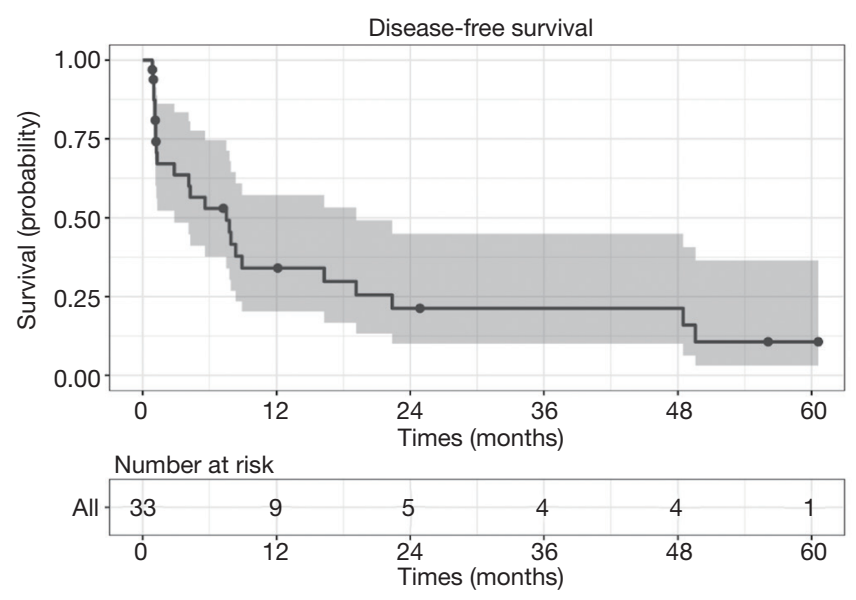

Figure 3 Disease-free survival Kaplan-Meier curve with 95\% confidence bands. in this study $80 \%$ of tumors were treated with multiple antennas and LTP was $4.1 \%$. In a different study with tumors of similar size $(1.7 \mathrm{~cm})$, only $22 \%$ of tumors were treated with $2+$ antennas and the LTP rate was 38\% (23). Notably, all four patients with LTP in this study occurred within the first four years of this study, suggesting that there may be a learning curve for $M W(43,44)$. It is important to consider that image-guided percutaneous ablation is a nascent treatment strategy that is currently highly reliant on individual physician experience and skill. There are several important emerging technological advances that will likely improve the consistency of outcomes across centers as well as continue to improve LTPFS (45-48). For example, semiautomated post-ablation margin analysis tools are becoming available, and these technologies can notify physicians of inadequate ablation margins at the time of the procedure (45-48). Given the known critical role that ablative margins play in LTPFS, retreatment of inadequate margins based on objective imaging criteria is likely to improve patient outcomes.

The overall and progression-free survival in this study cohort appeared highly favorable with a median OS of 52 months and 3 - and 5 -year survival rates of $66 \%$ and $47 \%$. These results appear to be approaching hepatic resection (49-53) and is concordant with a recently published matched cohort study in which MW ablation and hepatic resection have comparable OS rates (20). By way of comparison, prior CRLM MW studies report a median survival of $28-48$ months $(20,31,32)$ and a $33 \%(31)$ 5 -year survival, and radiofrequency ablation has a reported $18-48 \%(8-10,34,36,39)$ 5-year survival rate (Table 5).

Table 4 LTP tumor characteristics

\begin{tabular}{|c|c|c|c|c|c|c|c|c|}
\hline & $\begin{array}{l}\text { Time to } \\
\text { LTP (mo.) }\end{array}$ & $\begin{array}{l}\text { Size } \\
(\mathrm{cm})\end{array}$ & $\begin{array}{l}\text { Number of } \\
\text { antennas }\end{array}$ & Pathology & $\begin{array}{l}\text { Genetic } \\
\text { mutations? }\end{array}$ & $\begin{array}{l}\text { Prior liver } \\
\text { resection? }\end{array}$ & $\begin{array}{c}\text { Prior } \\
\text { chemotherapy? }\end{array}$ & $\begin{array}{c}\text { Extra-hepatic } \\
\text { disease? }\end{array}$ \\
\hline Tumor 1 & 15 & 1.6 & 2 & Adenocarcinoma & $\begin{array}{l}\text { KRAS: mutant; } \\
\text { BRAF: wild-type }\end{array}$ & $\mathrm{n}$ & $y$ & $\mathrm{n}$ \\
\hline Tumor 2 & 6 & 2.3 & 3 & $\begin{array}{l}\text { Composite tumor: } \\
\text { squamous cell carcinoma } \\
\text { with adenocarcinoma and } \\
\text { neuroendocrine features }\end{array}$ & $\mathrm{n} / \mathrm{a}$ & $\mathrm{n}$ & $y$ & $y$ \\
\hline Tumor 3 & 14 & 2.1 & 2 & Adenocarcinoma & $\begin{array}{l}\text { KRAS: wild-type; } \\
\text { BRAF: n/a }\end{array}$ & $\mathrm{n}$ & y & $y$ \\
\hline Tumor 4 & 50 & 3.5 & 3 & Adenocarcinoma & $\mathrm{n} / \mathrm{a}$ & $y$ & $y$ & $\mathrm{n}$ \\
\hline
\end{tabular}




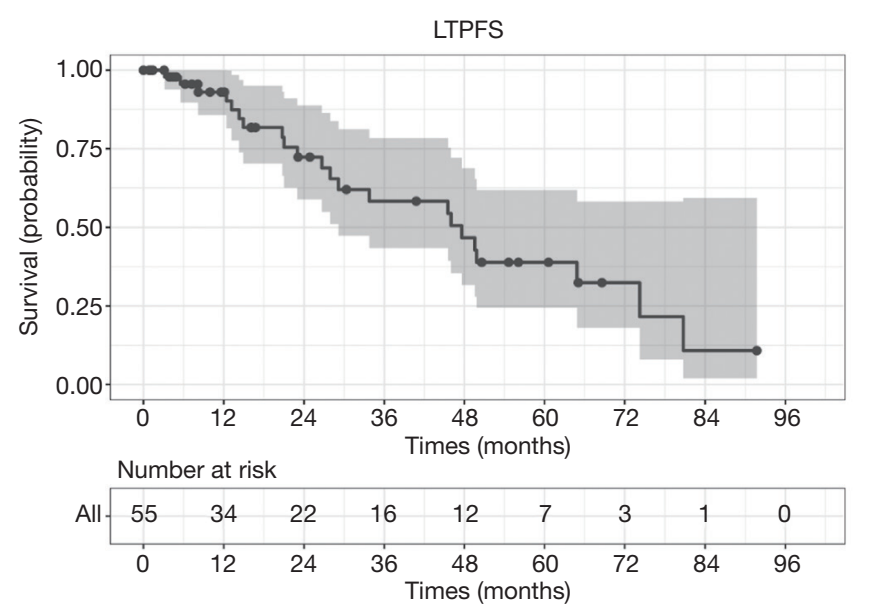

Figure 4 Local tumor progression free survival Kaplan-Meier curve with $95 \%$ confidence bands.

However, more definitive conclusions are not possible given that the patients in this study were selected by a multidisciplinary team for tumor size and location, and often had undergone the test-of-time for tumor biology by undergoing several prior lines of chemotherapy and local CRLM treatments (i.e., SBRT, Y90 or hepatic resection). A large percentage of patients in this cohort were also treated as part of a staged multi-treatment regimen which may have given patients a survival advantage as opposed to waiting for metachronous disease and then treating for salvage. This may account for the unexpected finding of potential improvements in survival for patients that received hepatic resection before ablation. Overall, one of the most important factors effecting patient survival in this study may be that $98 \%$ of patients received modern chemotherapy, with most receiving pre- and post-ablation treatment (54). Studies from earlier time points likely had higher proportions of patients treated with less effective chemotherapy, so survival comparisons across studies are interesting but limited.

There were no clear factors that predicted LTP in this study (Table 4). Other studies report that a KRAS mutation (55-57) (42\% of patients in this study), CRLM resection prior to ablation $(22,23,58)$, tumor size greater than $3 \mathrm{~cm}$ $(8,9,32,36,38,58)$, and ablative margins can influence LTP $(23,36,56-59)$. Since there were only 4 LTP events in this study, there was not enough statistical power to confirm earlier observations of the critical nature of ablative margins on LTPFS. There was no significant predictor of decreased OS in this study but slight associations $(\mathrm{P}=0.07)$ were noted for patients with extrahepatic disease and LTP. Factors reported in the ablation literature that decrease OS include extrahepatic disease $(8,9,39)$, KRAS mutation (55), more than one metastasis $(9,31,32,34,39)$, CEA $>10 \mathrm{ng} / \mathrm{mL}$ (31,34), and lesion size $>3 \mathrm{~cm}(8,9,31,32)$.

The rate of serious complications reported in this study was low with only three cases requiring further intervention: a single case each of pulmonary embolus, bile leak and abscess, and tract seeding in a patient with an aggressive cell type and prior biopsy. The patient with bile leak and abscess had a prior cholecystectomy but no common bile duct interventions-a known risk factor for intrahepatic abscess post-ablation $(58,60,61)$. Importantly, there were no cases of generalized peritoneal seeding such as those described in early trials of RF of HCC (62) or significant hepatic bleeding. The absence of these complications is likely due to the ability of all modern MW systems to perform tract ablation which was routinely performed at the study center. Overall, the types and frequency of complications in this study were mostly minor and similar to those described with RF and MW of HCC (61,63-65).

There were several limitations in this study. This is a single-center single-arm retrospective analysis in which a high number of patients received both systemic and local treatments pre- and post-ablation. This makes it challenging to attribute OS to a single intervention, and even more difficult to generalize and compare outcomes at different centers where multidisciplinary care, operator experience, patient demographics, and referral patterns may differ. Another important limitation is the rapidly evolving nature of oncologic therapies, most notably the advancement of chemotherapy regimens which makes comparison with earlier studies difficult. Finally, lack of a control group and the small sample size (57 patients) paired with a small number of events (4 LTP, 21 deaths) limits precision regarding parameter estimation within a Cox regression model and overall statistical power.

In summary, this single-center retrospective study of percutaneous ultrasound-guided MW ablation for CRLM demonstrates a high rate of technical success, few serious complications, and prolonged survival in selected patients. The low LTP rate in this study may be due to experienced operators, ultrasound guidance for probe placement and intra-procedural monitoring, and the use of multiple antennas in $80 \%$ of tumors. MW appears to be a promising 

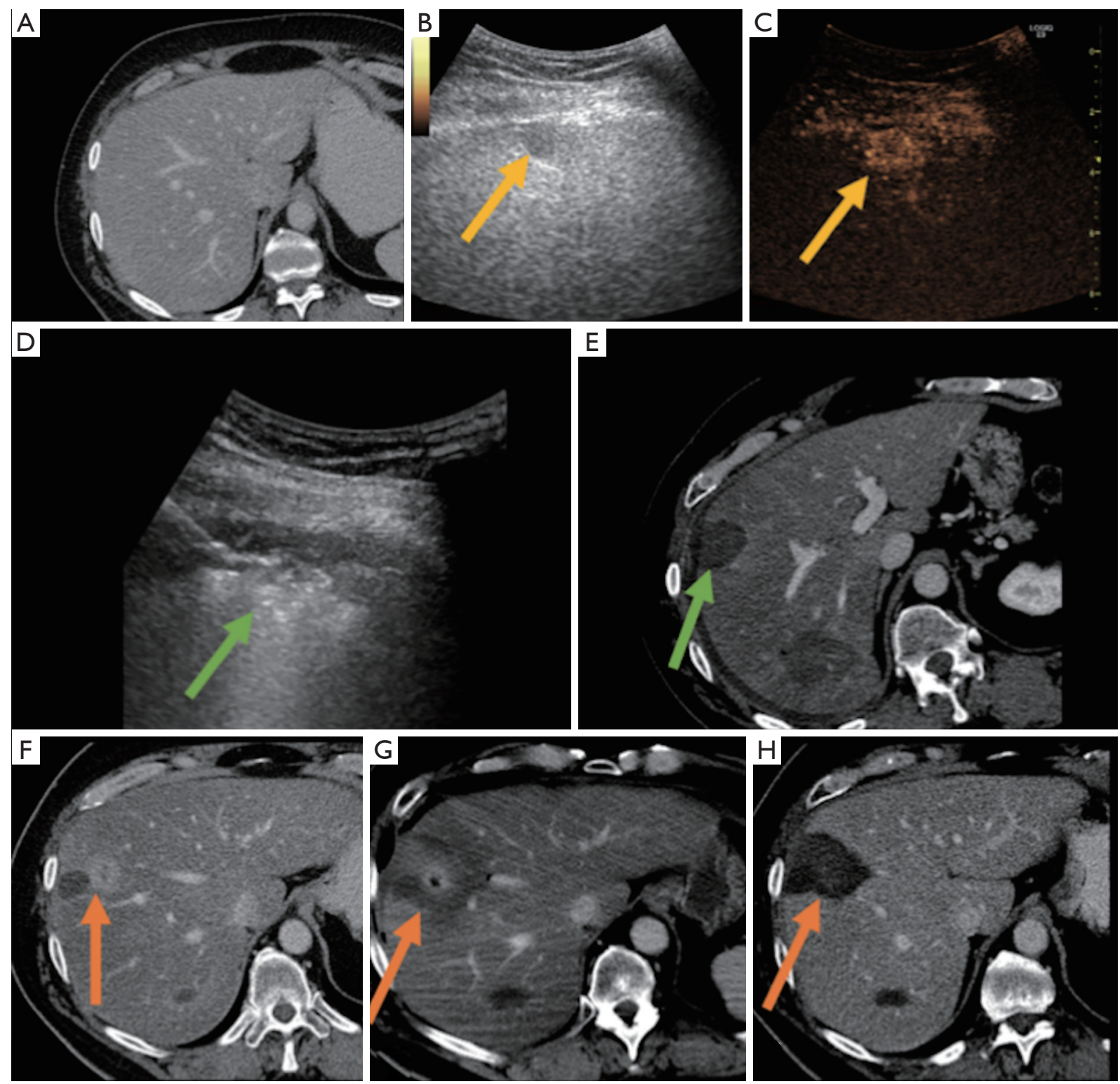

Figure 5 Example of local tumor progression with retreatment. (A) Segment VIII lesion in a 62-year-old male is radiographically occult on CT but visible by ultrasound. (B,C) US of lesion (yellow arrow) without and with US contrast. (D) Intra-procedural US demonstrating gas bubbles covering entire lesion (green arrow), and (E) post-ablation CT of lesion demonstrating appropriate coverage (green arrow). (F) New area of nodular enhancement detected along the medial ablation margin (orange arrow) 3 months post-ablation, consistent with LTP. (G) Repeat ablation shows appropriate coverage of LTP (orange arrow) without residual enhancing tissue. (H) Follow-up scan 4 months after retreatment demonstrates no recurrence (orange arrow). LTP, local tumor progression. 
Table 5 Comparison to recent published MW, cryo-, and RF percutaneous ablation studies for CRLM

\begin{tabular}{|c|c|c|c|c|c|c|c|c|c|c|c|}
\hline Study & Year & Modality & $\begin{array}{l}\text { No. of } \\
\text { patients/ } \\
\text { tumors }\end{array}$ & $\begin{array}{l}\text { Median or } \\
\text { mean tumor } \\
\text { size }(\mathrm{cm})\end{array}$ & $\begin{array}{l}\text { Median } \\
\text { follow-up } \\
\text { (months) }\end{array}$ & $\begin{array}{c}\% \\
\text { Extrahepatic } \\
\text { disease }\end{array}$ & $\begin{array}{c}\% \text { Major } \\
\text { complications }\end{array}$ & $\begin{array}{l}\text { LTP } \\
\text { rate }\end{array}$ & $\begin{array}{c}\text { Median OS } \\
\text { (months) }\end{array}$ & $\begin{array}{c}\text { 3-year } \\
\text { OS }\end{array}$ & $\begin{array}{c}\text { 5-year } \\
\text { OS }\end{array}$ \\
\hline $\begin{array}{l}\text { Sofocleous } \\
\text { et al. (33) }\end{array}$ & 2011 & $\mathrm{RF}$ & $56 / 71$ & 1.9 & 22 & $34 \%$ & $2 \%$ & $51 \%$ & 31 & $41 \%$ & $n / a$ \\
\hline $\begin{array}{l}\text { Bale } \\
\text { et al. (34) }\end{array}$ & 2012 & $\mathrm{RF}$ & $63 / 189$ & 2.0 & 25 & $0 \%$ & $17 \%$ & $16 \%$ & 33 & $44 \%$ & $27 \%$ \\
\hline $\begin{array}{l}\text { Solbiati } \\
\text { et al. (10) }\end{array}$ & 2012 & $\mathrm{RF}$ & $99 / 202$ & 2.2 & 72 & $7 \%$ & $1 \%$ & $12 \%$ & 53 & $69 \%$ & $48 \%$ \\
\hline $\begin{array}{l}\text { Shady } \\
\text { et al. (8) }\end{array}$ & 2016 & $\mathrm{RF}$ & $162 / 233$ & 2 & 55 & $31 \%$ & $7 \%$ & $48 \%$ & 36 & $48 \%$ & $31 \%$ \\
\hline $\begin{array}{l}\text { Littrup } \\
\text { et al. (37) }\end{array}$ & 2016 & Cryo- & $77 / 178$ & 2.9 & $22^{\dagger}$ & $\mathrm{n} / \mathrm{a}$ & $\mathrm{n} / \mathrm{a}$ & $11 \%$ & $\mathrm{n} / \mathrm{a}$ & $\mathrm{n} / \mathrm{a}$ & $\mathrm{n} / \mathrm{a}$ \\
\hline $\begin{array}{l}\text { Glazer } \\
\text { et al. (38) }\end{array}$ & 2017 & Cryo- & $(\mathrm{n} / \mathrm{a}) / 61$ & $2.5^{\dagger}$ & $(\text { mean }=30)^{\dagger}$ & $\mathrm{n} / \mathrm{a}$ & $11 \%^{\dagger}$ & $25 \%$ & $\mathrm{n} / \mathrm{a}$ & $\mathrm{n} / \mathrm{a}$ & $\mathrm{n} / \mathrm{a}$ \\
\hline $\begin{array}{l}\text { Knott } \\
\text { et al. }\end{array}$ & 2021 & MW & $57 / 102$ & 1.8 & 42 & $26 \%$ & $4 \%$ & $4 \%$ & 52 & $66 \%$ & $47 \%$ \\
\hline
\end{tabular}

technology for treatment of CRLM in combination with a multidisciplinary approach which includes modern chemotherapy and a variety of liver-directed therapies, and further comparative studies appear warranted.

\section{Acknowledgments}

We acknowledge the intellectual and technical contributions of the Biostatistics and Epidemiology Research Design
Core to the development of this manuscript.

Funding: In part, this work was funded by Institutional Clinical and Translational Science Award UL1 TR002373.

\section{Footnote}

Reporting Checklist: The authors have completed the STROBE reporting checklist. Available at https://dx.doi. org/10.21037/jgo-21-159 
Data Sharing Statement: Available at https://dx.doi. org/10.21037/jgo-21-159

Peer Review File: Available at https://dx.doi.org/10.21037/ jgo-21-159

Conflicts of Interest: All authors have completed the ICMJE uniform disclosure form (available at https://dx.doi. org/10.21037/jgo-21-159). TJZ receives research funding from HistoSonics Inc. and Ethicon Inc., is a shareholder of HistoSonics Inc., and is a consultant of Ethicon Inc.. SJL receives research funding from Incyte and Agios. JLH is a shareholder of Elucent Medical, Accure, HistoSonics Inc., and Cellectar and is a consultant of Ethicon Inc.. MGL received research funding previously from Philips and Ethicon Inc.. DA is a consultant of PatientPort. DD is a consultant of Array, Pfizer, Acrotech, MEI Pharma, Taiho, Bristol Myers Squibb, Promega, and Bayer and receives research funding from Merck, Revolution Medicine, Bayer, Promega, Genentech, and EMD Serono. NU is a consultant of QED, Ipsen, Taiho Inc., Incyte, and AstraZeneca, receives research funding from Taiho Inc., Eli Lilly, Ipsen, and EMD Serono, and has long position holdings in Natera and Exact Sciences. SAW is a consultant of Ethicon Inc.. PFL is a consultant of HistoSonics Inc. and Ethicon Inc., is a shareholder of HistoSonics Inc., and receives research funding from HistoSonics Inc.. MA is a consultant of Ethicon Inc.. FTL is a board member of HistoSonics Inc., is a consultant of HistoSonics Inc.. and Ethicon Inc., is a shareholder of HistoSonics Inc., receives research funding from HistoSonics Inc. and Ethicon Inc., and has patents/ royalties from Medtronic. The other authors have no conflicts of interest to declare.

Ethical Statement: The authors are accountable for all aspects of the work in ensuring that questions related to the accuracy or integrity of any part of the work are appropriately investigated and resolved. The study was conducted in accordance with the Declaration of Helsinki (as revised in 2013). The study was approved by the institutional ethics board of University of WisconsinMadison Health Sciences IRB (ID: 2012-0519) and individual consent for this retrospective analysis was waived.

Open Access Statement: This is an Open Access article distributed in accordance with the Creative Commons Attribution-NonCommercial-NoDerivs 4.0 International License (CC BY-NC-ND 4.0), which permits the non- commercial replication and distribution of the article with the strict proviso that no changes or edits are made and the original work is properly cited (including links to both the formal publication through the relevant DOI and the license). See: https://creativecommons.org/licenses/by-nc-nd/4.0/.

\section{References}

1. Bray F, Ferlay J, Soerjomataram I, et al. Global cancer statistics 2018: GLOBOCAN estimates of incidence and mortality worldwide for 36 cancers in 185 countries. CA Cancer J Clin 2018;68:394-424.

2. Zarour LR, Anand S, Billingsley KG, et al. Colorectal Cancer Liver Metastasis: Evolving Paradigms and Future Directions. Cell Mol Gastroenterol Hepatol 2017;3:163-73.

3. Wieser M, Sauerland S, Arnold D, et al. Peri-operative chemotherapy for the treatment of resectable liver metastases from colorectal cancer: A systematic review and meta-analysis of randomized trials. BMC Cancer 2010;10:309.

4. Kopetz S, Chang GJ, Overman MJ, et al. Improved survival in metastatic colorectal cancer is associated with adoption of hepatic resection and improved chemotherapy. J Clin Oncol 2009;27:3677-83.

5. Abdalla EK, Vauthey JN, Ellis LM, et al. Recurrence and outcomes following hepatic resection, radiofrequency ablation, and combined resection/ablation for colorectal liver metastases. Ann Surg 2004;239:818-25.

6. Wong SL, Mangu PB, Choti MA, et al. American Society of Clinical Oncology 2009 Clinical Evidence Review on Radiofrequency Ablation of Hepatic Metastases From Colorectal Cancer. J Clin Oncol 2010;28:493-508.

7. Benson AB, Venook AP, Al-Hawary MM, et al. Colon Cancer, Version 2.2021, NCCN Clinical Practice Guidelines in Oncology. J Natl Compr Canc Netw 2021;19:329-59.

8. Shady W, Petre EN, Gonen M, et al. Percutaneous radiofrequency ablation of colorectal cancer liver metastases: Factors affecting outcomes-a 10-year experience at a single center. Radiology 2016;278:601-11.

9. Hamada A, Yamakado K, Nakatsuka A, et al. Radiofrequency ablation for colorectal liver metastases: prognostic factors in non-surgical candidates. Jpn J Radiol 2012;30:567-74.

10. Solbiati L, Ahmed M, Cova L, et al. Small Liver Colorectal Metastases Treated with Percutaneous Radiofrequency Ablation: Local Response Rate and 
Long-term Survival with Up to 10-year Follow-up. Radiology 2012;265:958-68.

11. Wang X, Sofocleous CT, Erinjeri JP, et al. Margin size is an independent predictor of local tumor progression after ablation of colon cancer liver metastases. Cardiovasc Intervent Radiol 2013;36:166-75.

12. Veltri A, Sacchetto P, Tosetti I, et al. Radiofrequency ablation of colorectal liver metastases: small size favorably predicts technique effectiveness and survival. Cardiovasc Intervent Radiol 2008;31:948-56.

13. Ruers T, Van Coevorden F, Punt CJA, et al. Local Treatment of Unresectable Colorectal Liver Metastases: Results of a Randomized Phase II Trial. J Natl Cancer Inst 2017;109:djx015.

14. Di Martino M, Rompianesi G, Mora-Guzmán I, et al. Systematic review and meta-analysis of local ablative therapies for resectable colorectal liver metastases. Eur J Surg Oncol 2020;46:772-81.

15. Lubner MG, Brace CL, Hinshaw JL, et al. Microwave tumor ablation: mechanism of action, clinical results, and devices. J Vasc Interv Radiol 2010;21:S192-203.

16. Lubner MG, Brace CL, Ziemlewicz TJ, et al. Microwave ablation of hepatic malignancy. Semin Intervent Radiol 2013;30:56-66.

17. Leung U, Kuk D, D’Angelica MI, et al. Long-term outcomes following microwave ablation for liver malignancies. Br J Surg 2015;102:85-91.

18. Ziemlewicz TJ, Wells SA, Lubner MG, et al. Hepatic Tumor Ablation. Surg Clin North Am 2016;96:315-39.

19. Ahmed M, Brace CL, Lee FT, et al. Principles of and advances in percutaneous ablation. Radiology 2011;258:351-69.

20. Tinguely P, Dal G, Bottai M, et al. Microwave ablation versus resection for colorectal cancer liver metastases - A propensity score analysis from a population-based nationwide registry. Eur J Surg Oncol 2020;46:476-85.

21. Correa-Gallego C, Fong Y, Gonen M, et al. A retrospective comparison of microwave ablation vs. radiofrequency ablation for colorectal cancer hepatic metastases. Ann Surg Oncol 2014;21:4278-83.

22. Odisio BC, Yamashita S, Huang SY, et al. Impact of Prior Hepatectomy History on Local Tumor Progression after Percutaneous Ablation of Colorectal Liver Metastases. J Vasc Interv Radiol 2018;29:395-403.e1.

23. Shady W, Petre EN, Do KG, et al. Percutaneous Microwave versus Radiofrequency Ablation of Colorectal Liver Metastases: Ablation with Clear Margins (A0) Provides the Best Local Tumor Control. J Vasc Interv
Radiol 2018; 29:268-75.e1.

24. Gillams A, Goldberg N, Ahmed M, et al. Thermal ablation of colorectal liver metastases: a position paper by an international panel of ablation experts, The Interventional Oncology Sans Frontières meeting 2013. Eur Radiol 2015;25:3438-54.

25. De Cobelli F, Marra P, Ratti F, et al. Microwave ablation of liver malignancies: comparison of effects and early outcomes of percutaneous and intraoperative approaches with different liver conditions: New advances in interventional oncology: state of the art. Med Oncol 2017;34:49.

26. Meijerink MR, Puijk RS, van Tilborg AAJM, et al. Radiofrequency and Microwave Ablation Compared to Systemic Chemotherapy and to Partial Hepatectomy in the Treatment of Colorectal Liver Metastases: A Systematic Review and Meta-Analysis. Cardiovasc Intervent Radiol 2018;41:1189-204.

27. Denys A, Lachenal Y, Duran R, et al. Use of HighFrequency Jet Ventilation for Percutaneous Tumor Ablation. Cardiovasc Intervent Radiol 2014; 37:140-6.

28. Ahmed M, Solbiati L, Brace CL, et al. Image-guided tumor ablation: Standardization of terminology and reporting Criteria-A 10-year update. Radiology 2014;273:241-60.

29. Sacks D, McClenny TE, Cardella JF, et al. Society of Interventional Radiology Clinical Practice Guidelines. J Vasc Interv Radiol 2003;14:S199-202.

30. Cox DR. Regression Models and Life-Tables. J R Stat Soc Series B Stat Methodol 1972;34:187-220.

31. Shi Y, Wang Z, Chi J, et al. Long-term results of percutaneous microwave ablation for colorectal liver metastases. HPB (Oxford) 2021;23:37-45.

32. Urbonas T, Anderson EM, Gordon-Weeks AN, et al. Factors predicting ablation site recurrence following percutaneous microwave ablation of colorectal hepatic metastases. HPB (Oxford) 2019;21:1175-84.

33. Sofocleous CT, Petre EN, Gonen M, et al. CT-guided radiofrequency ablation as a salvage treatment of colorectal cancer hepatic metastases developing after hepatectomy. J Vasc Interv Radiol 2011;22:755-61.

34. Bale R, Widmann G, Schullian P, et al. Percutaneous stereotactic radiofrequency ablation of colorectal liver metastases. Eur Radiol 2012;22:930-7.

35. Tanis E, Nordlinger B, Mauer M, et al. Local recurrence rates after radiofrequency ablation or resection of colorectal liver metastases. Analysis of the European Organisation for Research and Treatment of Cancer 
\#40004 and \#40983. Eur J Cancer 2014;50:912-9.

36. Han K, Kim JH, Yang SG, et al. A Single-Center Retrospective Analysis of Periprocedural Variables Affecting Local Tumor Progression after Radiofrequency Ablation of Colorectal Cancer Liver Metastases. Radiology 2021;298:212-8.

37. Littrup PJ, Aoun HD, Adam B, et al. Percutaneous cryoablation of hepatic tumors: long-term experience of a large U.S. series. Abdom Radiol (NY) 2016;41:767-80.

38. Glazer DI, Tatli S, Shyn PB, et al. Percutaneous ImageGuided Cryoablation of Hepatic Tumors: Single-Center Experience With Intermediate to Long-Term Outcomes. AJR Am J Roentgenol 2017;209:1381-9.

39. Gillams AR, Lees WR. Five-year survival in 309 patients with colorectal liver metastases treated with radiofrequency ablation. Eur Radiol 2009;19:1206-13.

40. Lubner MG, Hinshaw JL, Andreano A, et al. Highpowered microwave ablation with a small-gauge, gascooled antenna: Initial ex vivo and in vivo results. J Vasc Interv Radiol 2012;23:405-11.

41. Harari CM, Magagna M, Bedoya M, et al. Microwave Ablation: Comparison of Simultaneous and Sequential Activation of Multiple Antennas in Liver Model Systems. Radiology 2016;278:95-103.

42. Ziemlewicz TJ, Hinshaw JL, Lubner MG, et al. Radiofrequency and microwave ablation in a porcine liver model: non-contrast CT and ultrasound radiologic-pathologic correlation. Int J Hyperthermia 2020;37:799-807.

43. Poon RT, Ng KK, Lam CM, et al. Learning curve for radiofrequency ablation of liver tumors: prospective analysis of initial 100 patients in a tertiary institution. Ann Surg 2004;239:441-9.

44. Hildebrand P, Leibecke T, Kleemann M, et al. Influence of operator experience in radiofrequency ablation of malignant liver tumours on treatment outcome. Eur J Surg Oncol 2006;32:430-4.

45. Keil S, Bruners P, Schiffl K, et al. Radiofrequency ablation of liver metastases-software-assisted evaluation of the ablation zone in MDCT: tumor-free follow-up versus local recurrent disease. Cardiovasc Intervent Radiol 2010;33:297-306.

46. Kaye EA, Cornelis FH, Petre EN, et al. Volumetric 3D assessment of ablation zones after thermal ablation of colorectal liver metastases to improve prediction of local tumor progression. Eur Radiol 2019;29:2698-705.

47. Laimer G, Jaschke N, Schullian P, et al. Volumetric assessment of the periablational safety margin after thermal ablation of colorectal liver metastases. Eur Radiol 2021. [Epub ahead of print]. doi: 10.1007/s00330-020-07579-x.

48. Vasiniotis Kamarinos N, Petre E, Camacho J, et al. Abstract No. 490 Three-dimensional assessment of the ablation zone margins with the Neuwave Ablation Confirmation software: a feasibility study. J Vasc Interv Radiol 2020;31:S216.

49. Nordlinger B, Sorbye H, Glimelius B, et al. Perioperative FOLFOX4 chemotherapy and surgery versus surgery alone for resectable liver metastases from colorectal cancer (EORTC 40983): long-term results of a randomised, controlled, phase 3 trial. Lancet Oncol 2013;14:1208-15.

50. Tzeng CW, Aloia TA. Colorectal liver metastases. J Gastrointest Surg 2013;17:195-201.

51. Robles-Campos R, Lopez-Lopez V, Brusadin R, et al. Open versus minimally invasive liver surgery for colorectal liver metastases (LapOpHuva): a prospective randomized controlled trial. Surg Endosc 2019;33:3926-36.

52. Sadot E, Groot Koerkamp B, Leal JN, et al. Resection margin and survival in 2368 patients undergoing hepatic resection for metastatic colorectal cancer: surgical technique or biologic surrogate? Ann Surg 2015;262:476-85.

53. Kemeny NE, Chou JF, Boucher TM, et al. Updated long term survival for patients with metastatic colorectal cancer treated with liver resection followed by hepatic arterial infusion and systemic chemotherapy. J Surg Oncol 2016;113:477-84.

54. Venook AP, Niedzwiecki D, Lenz H-J, et al. Effect of First-Line Chemotherapy Combined With Cetuximab or Bevacizumab on Overall Survival in Patients With KRAS Wild-Type Advanced or Metastatic Colorectal Cancer: A Randomized Clinical Trial. JAMA 2017;317:2392-401.

55. Shady W, Petre EN, Vakiani E, et al. Kras mutation is a marker of worse oncologic outcomes after percutaneous radiofrequency ablation of colorectal liver metastases. Oncotarget 2017;8:66117-27.

56. Odisio BC, Yamashita S, Huang SY, et al. Local tumour progression after percutaneous ablation of colorectal liver metastases according to RAS mutation status. Br J Surg 2017;104:760-8.

57. Calandri M, Yamashita S, Gazzera C, et al. Ablation of colorectal liver metastasis: Interaction of ablation margins and RAS mutation profiling on local tumour progressionfree survival. Eur Radiol 2018;28:2727-34.

58. Kurilova I, Bendet A, Petre EN, et al. Factors Associated With Local Tumor Control and Complications After Thermal Ablation of Colorectal Cancer Liver Metastases: A 15-year Retrospective Cohort Study. Clin Colorectal 
Cancer 2021;20:e82-e95.

59. Sotirchos VS, Petrovic LM, Gönen M, et al. Colorectal Cancer Liver Metastases: Biopsy of the Ablation Zone and Margins Can Be Used to Predict Oncologic Outcome. Radiology 2016;280:949-59.

60. Schullian P, Johnston E, Laimer G, et al. Frequency and risk factors for major complications after stereotactic radiofrequency ablation of liver tumors in 1235 ablation sessions: a 15-year experience. Eur Radiol 2021;31:3042-52.

61. Livraghi T, Meloni F, Solbiati L, et al. Complications of Microwave Ablation for Liver Tumors: Results of a Multicenter Study. Cardiovasc Intervent Radiol 2012;35:868-74.

62. Llovet JM, Vilana R, Brú C, et al. Increased risk of

Cite this article as: Knott EA, Ziemlewicz TJ, Lubner SJ, Swietlik JF, Weber SM, Zlevor AM, Longhurst C, Hinshaw JL, Lubner MG, Mulkerin DL, Abbott DE, Deming D, LoConte NK, Uboha N, Couillard AB, Wells SA, Laeseke PF, Alexander ML, Lee FT Jr. Microwave ablation for colorectal cancer metastasis to the liver: a single-center retrospective analysis. J Gastrointest Oncol 2021;12(4):1454-1469. doi: 10.21037/jgo21-159 tumor seeding after percutaneous radiofrequency ablation for single hepatocellular carcinoma. Hepatology 2001;33:1124-9.

63. Livraghi T, Solbiati L, Meloni MF, et al. Treatment of focal liver tumors with percutaneous radio-frequency ablation: complications encountered in a multicenter study. Radiology 2003;226:441-51.

64. Liang P, Wang Y, Yu X, et al. Malignant Liver Tumors: Treatment with Percutaneous Microwave AblationComplications among Cohort of 1136 Patients. Radiology 2009;251:933-40.

65. Lahat E, Eshkenazy R, Zendel A, et al. Complications after percutaneous ablation of liver tumors: a systematic review. Hepatobiliary Surg Nutr 2014;3:317-23. 